\title{
Morphometric analyses of human dry tali of South Indian origin
}

\author{
Manjunath V Motagi ${ }^{1}$, Sugathan R Kottapurath ${ }^{1}$, Kavitarati Dharwadkar ${ }^{2}$ \\ ${ }^{1}$ Department of Anatomy, Amala Institute of Medical Sciences, Thrissur, Kerala, India. \\ ${ }^{2}$ Amala Institute of Medical Sciences, Thrissur, Kerala, India. \\ Correspondence to: Manjunath V Motagi, E-mail: drmanjunathm@gmail.com \\ Received September 30, 2014. Accepted October 13, 2014
}

\section{Abstract}

Background: Talus is the key bone of the human body as it carries the whole weight of the body. Since the talus endures a lot of differential forces during locomotion, the stress patterns across the talus influence its overall dimensions. Research in skeletal biology and methodological approaches to the identification of human skeletal remains have advanced significantly in recent years. This study was undertaken because of the scarcity of the morphometric data in adult human dry tali of South Indian origin.

Objectives: The objectives of this study were to estimate the angles of declination and inclination in adult human dry tali; to estimate the differences in the angles between right and left tali; and to report and estimate the differences in other morphological parameters such as maximum anterioposterior length of the talus, maximum transverse width of the talus, trochlear length, length of the sulcus tali, and width of the sulcus tali of right and left sides.

Materials and Methods: The study was carried out on 50 (25 right and 25 left) adult dry tali of unknown ages and sexes over a period of 6 months in the Department of Anatomy, Amala Institute of Medical Sciences. The angles of declination and inclination were measured with goniometer. Other parameters were measured with digital Vernier calipers.

Results: The mean angles of declination were $26^{\circ}$ and $27^{\circ}$ and those of inclination were $120^{\circ}$ and $122^{\circ}$ on the right and left sides, respectively. All the parameters measured showed no statistically significant difference between the right and left sides.

Conclusion: The values of this study were relatively closer to the other studies. The parameters of this study may be helpful to surgeons, orthopedicians, and forensic anthropologists.

KEY WORDS: Talus, angle of inclination, angle of declination, club foot

\section{Introduction}

Talus is the one of the seven tarsal bones, and it is the link between the leg and foot through the ankle joint. ${ }^{[1]}$ Talus is the key bone as it carries the whole weight of the human body and communicates thrust from the one bone to the other. It is unique in the sense that it has neither tendon nor muscular attachments. $^{[2]}$ The talus is formed by three parts: the body (corpus tali), the neck (collum), and the head (caput). The body is defined as the part of the bone located posterior to an

\begin{tabular}{|l|l|}
\hline \multicolumn{2}{|c|}{ Access this article online } \\
\hline Website: htp://wnw.jimsph.com & Quick Response Code: \\
\hline &
\end{tabular}

imaginary plane passing through the anterior border of the superior surface of the trochlea of the tali and posterior calcaneal surface. The neck is the segment of the bone anterior to this plane, located between the body and the head. The body and the neck of the talus are not coaxial. In the horizontal plane, the neck shifts medially and makes an angle of declination $(A D)$ with the long axis of the trochlear tali; this angle is variable. In the sagittal plane, the neck is deviated downward relative to the talar body and makes an angle of inclination (Al). ${ }^{[3]}$ The talus is a good example of the plasticity exhibited by bones in response to mechanical requirements of new functions, which are imposed on it, as the talus encounter a lot of differential forces during locomotion. ${ }^{[4]}$ The stress patterns across the talus influence its overall dimensions, articular surface areas, and angles in particular. The variability of the aforementioned forces results in alterations of the morphology of the talus in terms of its angulations. ${ }^{[5,6]}$

Research in skeletal biology and methodological approaches to the identification of human skeletal remains have advanced significantly in the recent years. Knowledge 
about the affinities of populations and determinations of sex, race, age, and stature has increased significantly as a result of the increased population-specific studies and the publication of reviews in the fields of forensic and physical anthropology. ${ }^{[7]}$ Standards for skeletal identification vary between populations, and the standards for one population may not be used for another. $^{[8]}$ There is a paucity of morphometric data of the human tali in South Indian population, and this study will be helpful to surgeons for surgical interventions during the treatment of talar neck fractures caused by trauma, in designing talar body prostheses, and in aligning the bones in the treatment of congenital talipes equinovarus (CTEV) or club foot. It is also useful for forensic anthropologists.

\section{Objectives}

The objectives of this study were:

- To estimate the $\mathrm{AD}$ and $\mathrm{Al}$ in adult human dry tali;

- To estimate the differences in Al and AD between the right and left tali; and

- To report and to estimate the differences in other morphological parameters such as maximum anterioposterior length of the talus (MAPL), maximum transverse width of the talus (MTW), trochlear length (TL), length of the sulcus tali (LS), and width of the sulcus tali (WS) of the right and left sides.

\section{Material and Methods}

This study was an analytical, cross-sectional study, which was performed on 50 ( 25 right and 25 left) adult dry tali of

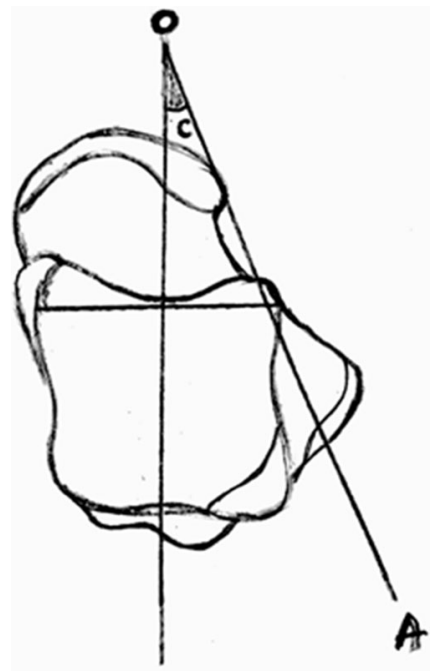

B

Figure 1: Method of measurement of angles of declination (AD) by goniometer with the reference points. unknown ages and sexes over a period of 6 months in the Department of Anatomy, Amala Institute of Medical Sciences, Thrissur, Kerala, India. Damaged and pathologically abnormal bones were excluded from the study. The angles $A D$ and $A I$ were measured with goniometer. The $A D$ was measured with goniometer with the reference points as shown in Figure 1. One arm of the goniometer was placed along the longitudinal axis of the body, which was kept along the center of the trochlear surface, i.e., in line BO, and the other arm was placed along the upper part of lateral border of the neck of the talus, which determines the longitudinal axis of the neck, i.e., in line $\mathbf{A O}$. The subtended angle $\mathbf{C}$ between the arms was taken as $\mathrm{AD}$. The $\mathrm{Al}$ was also measured with goniometer with the reference points as shown in Figure 2. One arm of the goniometer was placed along the line $\mathbf{O A}$, which is horizontal; the point $\mathbf{O}$ is the midpoint of the medial trochlear arch. The other limb of the goniometer was placed in such way that it was directed along the midpoint of the navicular articular surface, which was along the line OB. Point $\mathbf{B}$ is the midpoint of the navicular articular surface. The angle subtended between line $\mathbf{O A}$ and $\mathbf{O B}$, i.e., angle $\mathbf{I}$, is the inclination angle. Some authorities add $90^{\circ}$ to the angle I to express it. In this study, we have also added $90^{\circ}$ to the angle I to express Al. Other parameters, MAPL, MTW, TL, LS, and WS, were measured using digital Vernier calipers.

\section{Statistical Analysis}

For all the parameters, mean, standard deviation, and standard error of means were calculated with SPSS software version 16. We used unpaired " $t$ " test to see whether there was any statistically significant difference between the parameters of the right and left sides.

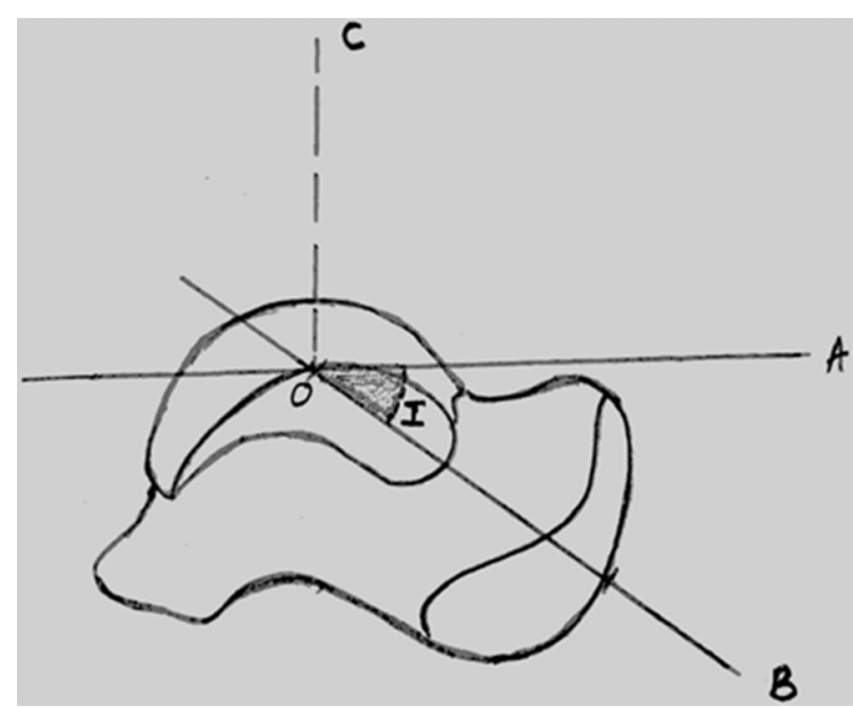

Figure 2: Method of measurement of angles of inclination (Al) by goniometer with the reference points. 
Table 1: Measurements of various parameters in human tali

\begin{tabular}{|c|c|c|c|c|c|c|c|}
\hline & Parameters & $\mathbf{N}$ & Mean & SD & SEM & $t$ Value & $P$ value \\
\hline \multirow[t]{2}{*}{$A D$} & Right (R) & 25 & $26^{\circ}$ & 11.232 & 2.246 & 0.317 & 0.753 \\
\hline & Left (L) & 25 & $27^{\circ}$ & 11.083 & 2.217 & & \\
\hline $\mathrm{Al}$ & $\mathrm{L}$ & 25 & $122^{\circ}$ & 7.552 & 1.51 & & \\
\hline \multirow[t]{2}{*}{ MAPL } & $\mathrm{R}$ & 25 & $5.422 \mathrm{~cm}$ & 0.448 & 0.089 & 0.677 & 0.502 \\
\hline & $\mathrm{L}$ & 25 & $5.335 \mathrm{~cm}$ & 0.447 & 0.091 & & \\
\hline MTW & $\mathrm{L}$ & 25 & $3.777 \mathrm{~cm}$ & 0.299 & 0.059 & & \\
\hline \multirow[t]{2}{*}{ TL } & $\mathrm{R}$ & 25 & $2.957 \mathrm{~cm}$ & 0.286 & 0.057 & 0.617 & 0.540 \\
\hline & $\mathrm{L}$ & 25 & $3.00 \mathrm{~cm}$ & 0.262 & 0.052 & & \\
\hline \multirow[t]{2}{*}{ LS } & $\mathrm{R}$ & 25 & $1.895 \mathrm{~cm}$ & 0.314 & 0.062 & 1.516 & 0.136 \\
\hline & $\mathrm{L}$ & 25 & $1.755 \mathrm{~cm}$ & 0.337 & 0.067 & & \\
\hline \multirow[t]{2}{*}{ WS } & $\mathrm{R}$ & 25 & $0.720 \mathrm{~cm}$ & 0.140 & 0.028 & 0.169 & 0.866 \\
\hline & $\mathrm{L}$ & 25 & $0.727 \mathrm{~cm}$ & 0.143 & 0.028 & & \\
\hline
\end{tabular}

\section{Results}

The results of this study are tabulated in Table 1.

The $P$ values of all the parameters showed that there is no statistically significant difference between the parameters of the right and left sides.

\section{Discussion}

In this study, we observed that mean AD was $26^{\circ}$ and $27^{\circ}$ and mean $\mathrm{Al}$ was $120^{\circ}$ and $122^{\circ}$, on the right and left sides, respectively. According to the Gray's anatomy, ${ }^{[1]}$ neck-body angle of the talus was described as the long axis of the neck, inclined downward, distally and medially, and makes an angle of approximately $150^{\circ}$ with that of the body, ${ }^{[1]}$ which indicates

Table 2: Comparison of mean values of $A D$ and $A l$ in different studies

\begin{tabular}{lcc}
\hline Authors & Mean AD $\left(^{\circ}\right)$ & Mean Al $\left(^{\circ}\right)$ \\
\hline Testut $^{[0]}$ & 22 & 115 \\
Paturet $^{[10]}$ & $22-30$ & 115 \\
Sarrafian's anatomy $^{[13]}$ & 24 & 114 \\
This study & 26.5 & 121 \\
\hline
\end{tabular}

that neck-body angle of $150^{\circ}$ includes both declination and inclination angles. In this study, if both the means of $A D$ and Al were added together, it will be $146^{\circ}$ on the right side and $149^{\circ}$ on the left side, which were comparable with the values mentioned in Gray's anatomy. In Sarrafian's anatomy, neck-body angle was described as the body and neck of the talus, which are not coaxial. In the horizontal plane, the neck shifts medially and makes an angle of declination with the long axis of the trochlear tali. In the sagittal plane, the neck is deviated downward relative to the talar body and makes an angle of inclination. The mean values of $A D$ and $A l$ of this study were compared with those of other studies as shown in Table 2.

The other parameters of this study were compared with those parameters studied by various authors, as depicted in Table 3. From Table 3, we can presume that mean values of MAPL, MTW, TL, and LS of this study were relatively closer to the mean values of the other studies. As far as mean values of WS of this study was concerned, a relatively wide variation can be noted among various studies.

The $P$ values of all the parameters in this study showed that there is no statistically significant difference between the parameters of the right and left sides. These observations were similar to those made by other authors except the study by Ari and Kafa, ${ }^{[11]}$ where the authors reported significant side differences of LS and WS parameters.

Table 3: Comparison of other parameters in different studies

\begin{tabular}{|c|c|c|c|c|c|c|c|c|c|c|}
\hline \multirow[t]{2}{*}{ Authors } & \multicolumn{2}{|c|}{ MAPL (cm) } & \multicolumn{2}{|c|}{ MTW (cm) } & \multicolumn{2}{|c|}{$\mathrm{TL}(\mathrm{cm})$} & \multicolumn{2}{|c|}{ LST (cm) } & \multicolumn{2}{|c|}{ WST (cm) } \\
\hline & $\mathbf{R}$ & $\mathbf{L}$ & $\mathbf{R}$ & $\mathbf{L}$ & $\mathbf{R}$ & $\mathbf{L}$ & $\mathbf{R}$ & $\mathbf{L}$ & $\mathbf{R}$ & $\mathbf{L}$ \\
\hline Ari and $\mathrm{Kafa}^{[11]}$ & 5.72 & 5.64 & 4.91 & 4.69 & 3.15 & 3.08 & 1.76 & 2.10 & 0.38 & 0.48 \\
\hline Mahato and Murthy ${ }^{[12]}$ & 5.57 & 5.58 & 2.90 & 3.03 & - & - & 2.46 & 2.62 & 1.50 & 1.44 \\
\hline Gautham et al..$^{[13]}$ & 5.23 & 5.29 & 3.79 & 3.68 & 3.06 & 3.04 & 2.01 & 2.04 & 0.68 & 0.67 \\
\hline This study & 5.42 & 5.33 & 3.62 & 3.77 & 2.95 & 3.00 & 1.89 & 1.75 & 0.72 & 0.72 \\
\hline
\end{tabular}




\section{Conclusion}

In this study, the parameters studied showed no significant statistical differences between the right and left sides. However, we observed that the values of this study were relatively closer to the other studies. This study may be helpful to surgeons for surgical interventions for the treatment of talar neck fractures, for designing talar body prostheses, and for aligning the bones in the treatment of CTEV and to the forensic anthropologists.

\section{References}

1. Williams PL, Bannister LH, Berry MM, et al. (Eds.). Gray's Anatomy, 38th edn. Edinburgh: Churchill Livingstone, 1999.

2. Last RJ. Anatomy Regional and Applied, 4th edn. English Language Book Society and J.A. Churchill, Edinburgh, 1970. pp. 303-5.

3. Sarrafian SK. Anatomy of the Foot and Ankle: Descriptive, Topographic, Functional. Philadelphia, PA: Lippincott, 1983. pp 400-7.

4. Appleton AB. Postural deformities and bone growth. Lancet, 1934;224:451-4.

5. Leardini A. Geometry and mechanics of the human ankle complex and ankle prosthesis design. Clin Biomech. 2001;16:706-9.

6. Magerkurth $\mathrm{O}$, Knupp M, Ledermann H, Hintermann B. Evaluation of hindfoot Dimensions: a radiological study. Foot Ankle Int. 2006;27:612-16.
7. Scheuer L. Application of osteology to forensic medicine. Clin Anat. 2002;15(4):297-312.

8. Cattaneo C. Forensic anthropology: developments of a classical discipline in the new millennium. Forensic Sci Int. 2007;165(2-3): 185-93.

9. Testut L. Traite d Anatomie Humaine, Vol. 1, 7th edn. Paris: O. Doin, 1921. p. 368.

10. Paturet G. Traite d Anatomie Humaine, Vol. 2. Paris: Masson, 1951.

11. Ari I, Kafa IM. Bone length estimation and population-specific features of calcaneus and talus bones of the late byzantine era. Coll Antropol. 2009;33(2):613-18.

12. Mahato NK, Murthy SN. Articular and angular dimensions of the talus: inter-relationship and biomechanical significance. Foot (Edinb). 2012;22:85-9.

13. Gautham K, Clarista $M Q$, Sheela N, Vidyashambhava $P$. Morphometric analysis of the human tali. CIBTech J Surg. 2013;2(2):64-8.

How to cite this article: Motagi MV, Kottapurath SR, Dharwadkar $\mathrm{K}$. Morphometric analyses of human dry tali of South Indian origin. Int J Med Sci Public Health 2015;4:237-240

Source of Support: Nil, Conflict of Interest: None declared. 